

\section{Glossary of Terms}

\begin{tabular}{|c|c|}
\hline AWN & Afghan Women's Network \\
\hline MoE & Ministry of Economy \\
\hline MoWA & Ministry of Women's Affairs \\
\hline GA & General Assembly \\
\hline UNSCR & United Nations Security Council Resolution \\
\hline NGOs & Non-governmental Organizations \\
\hline HPC & High Peace Council \\
\hline CSOs & Civil Society Organizations \\
\hline M\&E & Monitoring and Evaluation \\
\hline PMIS & Programme Management Information System \\
\hline H. E & His Excellency \\
\hline EVAW & Elimination of Violence against Women \\
\hline CEDAW & Convention on Elimination of Discrimination against Women \\
\hline OBR & One Billion Raising \\
\hline DFAT & Department of Foreign Affairs and Trade \\
\hline DFID & Department of Foreign International Development \\
\hline
\end{tabular}

\section{Afghan Women's Network General Assembly Election}




\section{Report 02/03/2016}

AWN's board is a body of elected members who jointly oversee the activities of Afghan Women's Network combination of seven women activist. These board members are elected after two years through transparent process of voting by AWN's individual members, NGOs members

This year Afghan Women's Network conducted its general assembly on 2nd March 2016. The GA is conducted regularly after each two years. Through this GA the AWN elected its seven board members through a transparent election process. The session inaugurated by recitation few of holy Quran and playing national anthem.

The session was initiated with welcoming speech of Ms. Hasina Safi, AWN's executive director and defined an over view of the network and recent updated information accomplished during the past two years (February, 2014 - February, 2016).

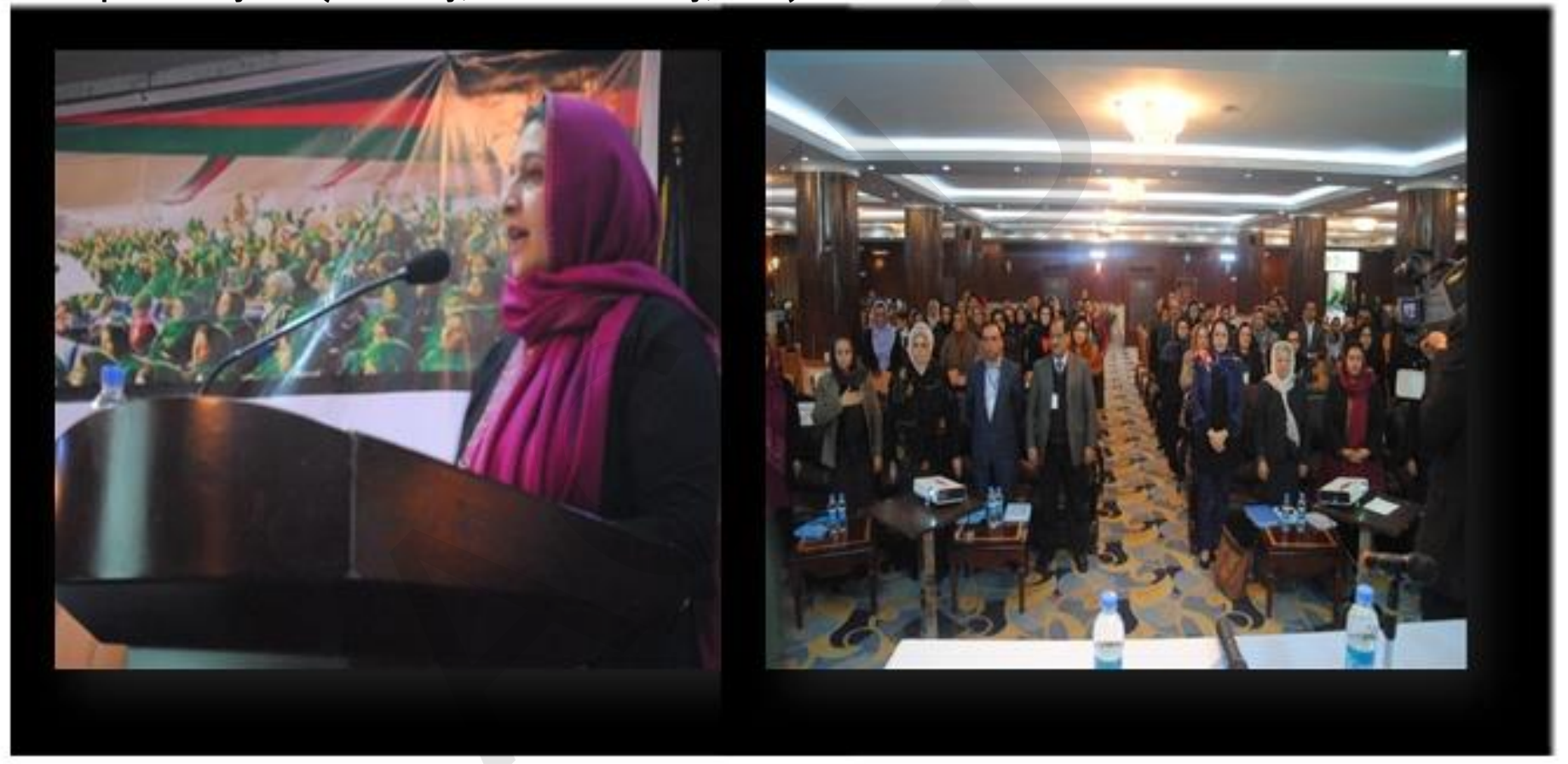

Her presentation was prepared based on institutional development and AWN's strategic focus areas 1) Women's Political Participation and Leadership; 2) Women's Legal \& Social Protection and; 3) Women's Peace and Security.

\section{Institutional Development:}

Ms. Hasina Safi elaborated the changed and improvements taken place with the network, she said, in institutional development, the contents of AWN's network constitution improved inclusively in line with the network requirements, moreover AWN's strategic plan for the year 2015-2017 indicating budget and other essential information.

AWN also increased its presence to the zonal level aiming to facilitate and service more women through opening new five zonal offices in Paktia, Kunduz, Balkh, Kandahar and 
Bamyan provinces as hub lead by a provincial manager and cover its three neighbouring province lead by a focal point. Moreover, she also thanked to Ms. Nabila Muslih deputy minister of MOWA for his active participation and said, the network support will be always with you.

Establishment of the zonal offices reached to active and considerable presence of AWN in Kabul, Herat, Balkh, Kandahar, Bamyan, Paktia, Nangarhar and Kunduz, and also became active through its member in other provinces of Afghanistan. Meanwhile, over the past two years through the core funds, AWN managed revised and developed new polices and manuals to the for the growth of the network. The purposed of these documents considered as to establish the policies and procedures of AWN with regard to communication, fundraising, procurement, security, information technology, branding, and advocacy that help the AWN to develop and maintain the line of the relationships with the donor agencies ultimately resulting in longer sustainability of organization, as well as, to ensure that all activities are well managed, deliberate, are reliable and valued by the staff and stakeholders.

Ms. Hasina elaborated that These AWN's documents which developed, edited and revised recognised the needs for a range of style of the AWN that will contributes to the overall project and organizational goal "institutional development and to empower Afghan Women and ensure their equal representation and participation in Afghan Society.

She added that we gained significant improvement and achievements in areas of upgrading information technology, such as, upgrading Website, Servers, Social Media, including, Facebook, Twitter and Linkedln - Monthly Newsletter, Layout of the Press Release. She added the purpose of the developing and producing these documents are to disseminate information about AWN activities, Partners, Ponors and Member Organisations and reflect the AWN's policies, activities and strategies in relation to women accessibility to the interested parties.

Establishment of the resource centres within the eight sub-national offices of Nangarhar, Herat, Paktia, Bamyan, Kandahar, Balkh, Kunduz and head office as chamber to control other resource centres available at zonal level.

She cleared the purpose for establishment of the resource centres as to provide easy access and exchange the updated information between AWNs members and partner organization and to strongly conduct joint advocacy for the women's exposed violence or their legal rights are violated by any organs by all means. The resource centre also functions as warehouse for keeping the AWN's projects reports, documents, legislations, documentaries and policies translated in three languages (Dari, Pushto and English) and will be available to the women at community level, governmental officials visiting the RC.

The centres also equipped with computers and internet facilities to allow members to be connected and share information efficiently. The resource centres provide information in English, Dari and Pashto, making it accessible at the provincial and district levels through online sources. They will also provide information on how in-need women can be benefited from the different projects, services and resources available for women.

The centres catalogue information according to topics, ensure access to all registered in network and will be managed by trained resource centre officers. This platform will create efficient advocacy strategies and allow for quicker responses when required. 
She concluded that AWN has 126 active NGO members and 3500 individual members.

\section{Women's Political Participation and Leadership}

Ms. Hasina highlighted, AWN has three strategic focus areas in which actively functioning operation to gain achievements for improvements of women's status at the community ground, increase involvements of women at governmental sector, intensify and increase the awareness of community members and governmental officials on women's role in peace talks and peace negotiation.

She added under the political Participation and leadership focus area over the past two years, AWN initiated a pilot project in Kabul called 'Young Women's Leadership Program'. The aim of the programme is to recruit promising young women who will be trained on a variety of issues, including leadership skills, political and civil engagement, peace processes, gender concepts, women's rights laws and policies amongst others. this is a ten months training programme for ten female participants that intends to establish a sustainable resource for advancing gender equality in Afghanistan. This initiative runs for 10 months each year in 2 cohorts.

In addition, the AWN facilitated a coordination meeting between the women at ministerial candidates aiming to provide the groundwork to the female candidates to share their working platform with women before they go to the parliament for voting.

She added, to highlight the progress, challenges and recommendation for women's political participation and leadership, AWN developed a research throughout the country aiming

\section{Women's Legal and Social Protection}

Under this component over the past two years we have done a lot of impact based significant activities but not limited to including a fact based report on EVAW, linking advocacy coalitions from the provincial to the national level aiming to include their recommendation to national policy, celebration of 8th March, celebration of OBR, celebration of 16 days of activism, broadcasting of radio spots and CEDAW alternative and so on.

\section{Women's Peace and Security}

\section{For Women's Peace and Security, AWN}

accomplished impact based significant activities but not limited to including UNSCR 1325 scorecard aiming to review the resolution implementation during the past four years and its impact on women's lives. moreover, research on APRP gender policy, mobilization and establishment of women's advocacy coalitions in seven zones, Developing policy paper on women's peace and security concerns, Research on Production of 1325 monitoring report at national \& sub-national level, Celebration of Peace day at national and sub-national level

Advocacy:

$>$ Farkhunda Immediate-Intermediary-Long Term

EVAW Law Exception Law

$>$ Cabinet Coordination Meeting

$>$ HPC Provincial Peace Councils 
Election Reform Commission Nominees

$>$ Open letter to president for $25 \%$ of quota PD

$>$ Representation of AWN in Penal code

$>$ Shelter Coordination Committee MOWA

\section{Networking}

CSO Members 126

$>$ Individual Members 3500

$>$ Tawanmandi Joint Networking Strategy >

Membership Policy

$>$ Networking Manual

$>$ Capacity building training to members on Networking $>$ Capacity Building

$>$ AWN Program Capacity Assessment

$>$ Mentoring of Secretariat

$>$ Member organization assessment (through e-mail) $>$

Capacity building workshop

$>$ Mentoring Women Police Councils

\section{Implementation of the newly developed policies}

$>$ Finance

$>$ Programme $/ \mathrm{M} \& \mathrm{E}$

$>$ Monitoring

$>$ PIMS

$>$ Resource Centre (Soft \&hard) data base pilot operating $>$ Monthly Newsletter

\section{Finance}

Annual Budget 2015: \$ 2482414

Secured Budget \%: 2217384

$>$ Deficit \%: 265030

2015 Donors: Tawanmandee, AusAid (DFAT), EC, UNOPS >

Progress: Cordaid, Norway, Canada Save the Children $>$ Audit:

In Progress

\section{Human Resource}

$>$ Total number of staff:

107(69F, 38M)

Kabul Staff:

$42(24 \mathrm{~F}, 20 \mathrm{M})$

Regional office Staff:

07

\section{Challenges:}


Significant increase in secretariat has been a challenge

$>$ Peoples more expectation beyond the networks responsibility

$>$ Peoples negative perception pertaining that the network performance is brought poor $>$ In 2010 and 2011 negative competitions between eh CSOs has been a challenge

After that Ms. Nabila Muslih the deputy minister of MOWA presented the message of H.E minster of MOWA and appreciated the AWN works and pledged its lifetime support with network.

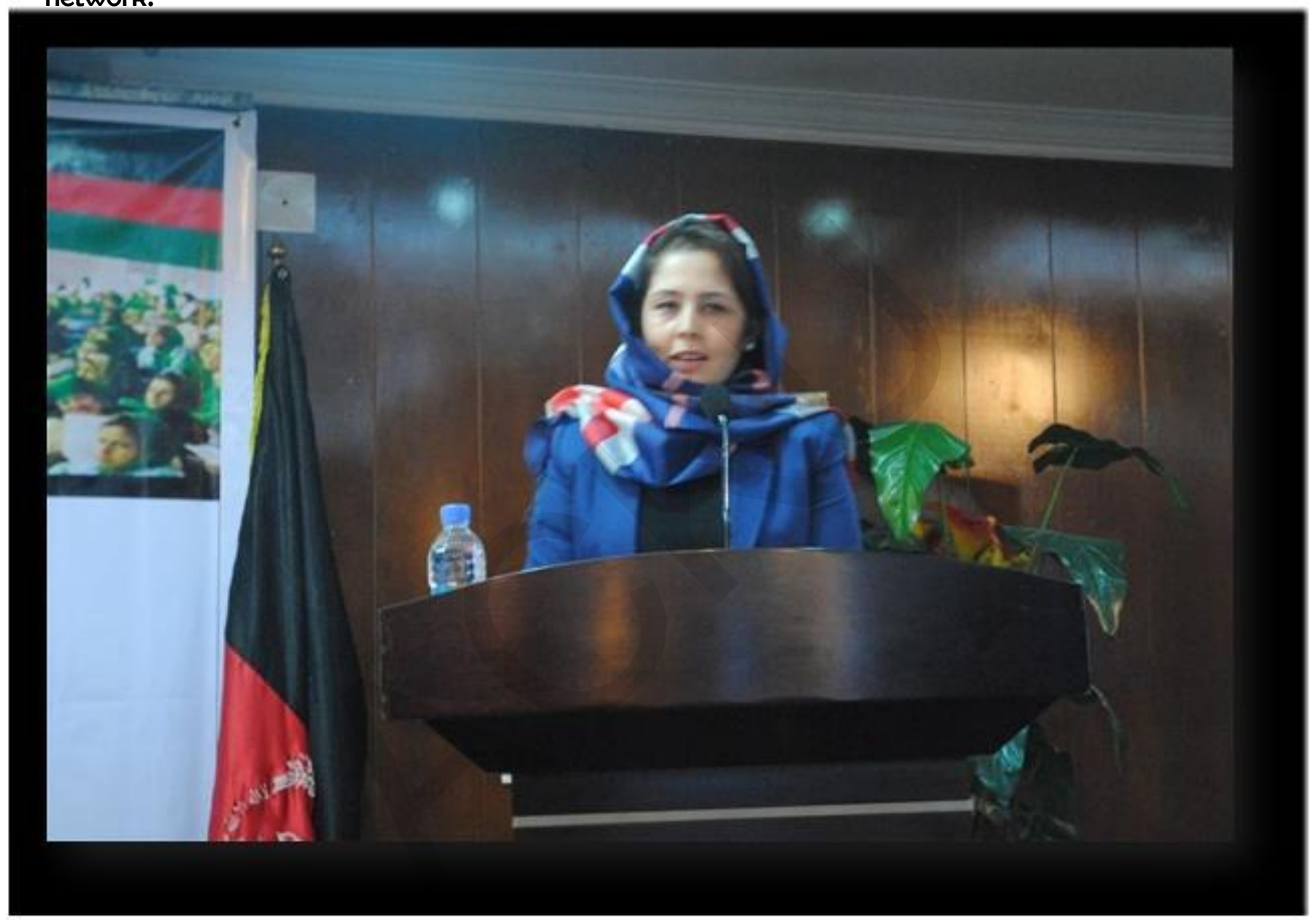

Following to that, Hangama Anwari, EVAW law program manager welcomed the AWN efforts and initiative especially during the past thirteen years in relation to the afghan women at national and international levels. She added, challenges exist in every organization but it's important to keep in mind the lesson learns and use it as a strength in the future.

UN women supports all NGOs working for women's rights. Our support and CSOs contributions will lead us to gender equality in Afghanistan. We also, support the CSOs engagement at policy level. And I strongly pledge the UN Women future contribution with AWN. 
MR. Hashim Baseerat head of NGOs said, despite of challenges network survives and functions well and it's a great achievement to the network. During the past 10 years the AWN reports and productive operations attend the satisfaction and support of the international community and it's all resulting of generation decisions being made at AWN. The MOE has a good well before the network. Its accountability, transparency and productive operations proved it.

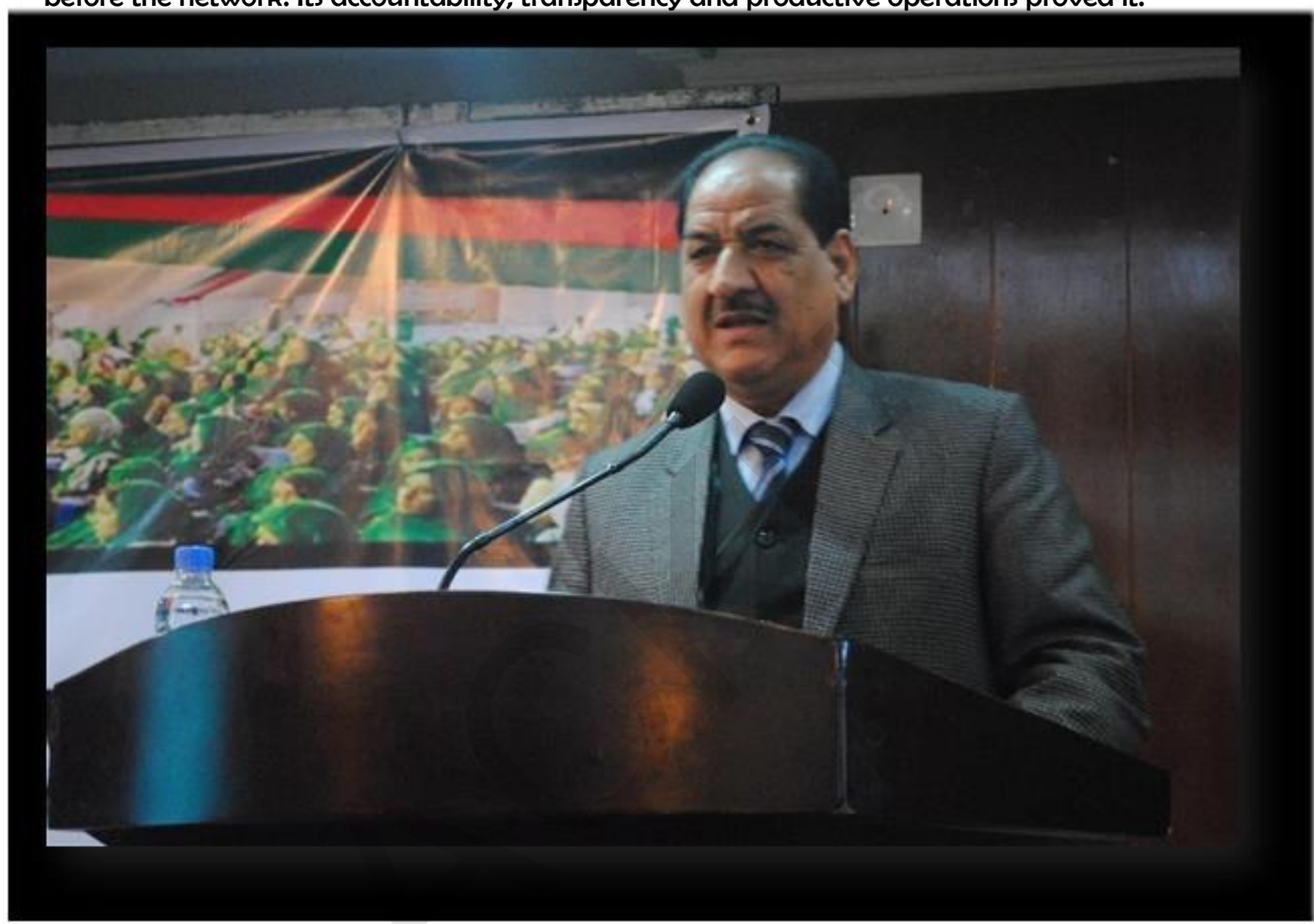

Mari Akrami, Ex-chairman board of AWN briefly talked over the past two years' achievements and thanked to the AWN founders Ms. Palwasha Hassan, Khorshid Noori, Asial Wardak, Najia as well as to the AWN secretariat for their tireless efforts.

MS. Palwasha Hassan, AWN's founders' briefly defined the election process as follow: total 14 people nominated themselves to the AWN board of directors including seven Ex-board member, senior member of the network and individuals who have active contribution with the AWN over the past two years. This the tent GA being conducted.

The first GA was conducted in 1995 in Islamabad, Pakistan and first constitution was also, made in1998 in Islamabad Pakistan.

Finally, Ms. Roshan Mashal networking manager of AWN introduced each candidates and asked them to introduce themselves and present their platform within five minutes.

AWN Board 's Candidates 
1. Shafiqa Habibi

2. Ustad Shahla Farid ( $x$-board member 2014-2016)

3. Zarq Yaftali ( $x$-board member 2014-2016)

4. Nooria Safi

5. Samira Hamidi ( $x$-board member 2014-2016)

6. Mari Akrami (x-board member 2014-2016)

7. Roshan Sirran

8. Mariam Rahmani ( $x$-board member 2014-2016)

9. Gulmakai Siawash ( $x$-board member 2014-2016)

10. Mahbouba Seraj

11. Hasina Hasin

12. Karima Hedayat

13. Sima Rasooly

Each one of the abovementioned AWN's board candidates talked for less or more five minutes and defined their future plans. It's worth to mention that Ms. Mahbooba Seraj speech was read by AWN's secretariat as she was abroad the country.

\section{Voting Process}

After that, the voting boxes put in places and voting ballots distributed to the members who had voting rights by $A W N$ secretariat. For more transparency the AWN secretariat distributed membership cards to those who had AWN's individual or organizational membership and

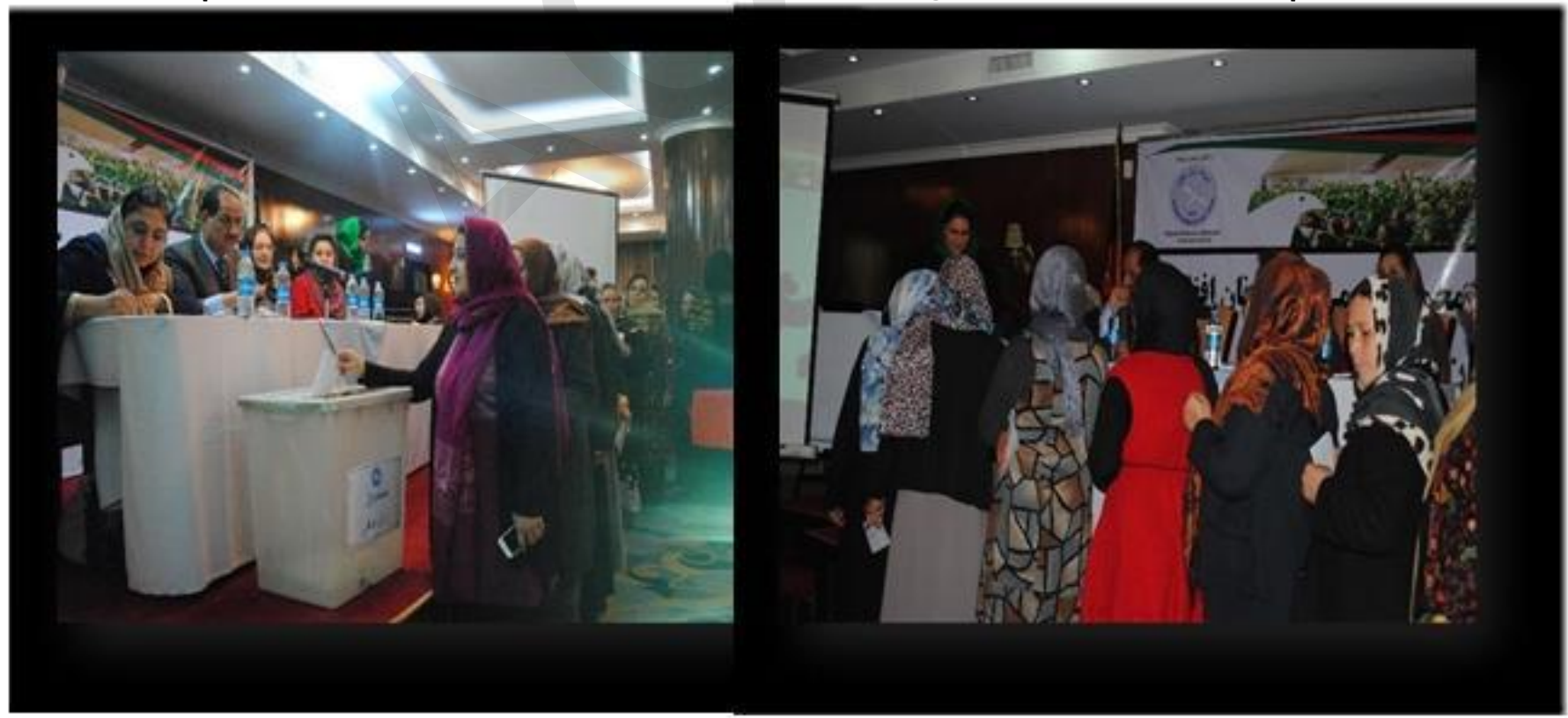

guest cards to those who accompanied the AWN members and they had no voting rights. And during the voting only those who had membership cards had the right to vote and were by observers to hand in their cards and receive a ballot card in return. An observers' committee 
formed to assure transparency in the voting process. The observers group were consisting of Mr. Hashim Baseerat, head of NGOs at MoE, Ms. Sema Natiq from ACBAR and Hassina Nikzad AWN provincial manager.

After the voting process the votes counted in the presence of observers including H.E Dr. Nasreen Oriakhil, Minister of Labour and Social Affairs, Ms. Nabila Muslih deputy minister of MoWA, Mr. Said HAshim BAseerat Head of NGOs at MoE, and Ms. Hangama Anwari Programme manager of UN-Women, in which Ms. Shahla Farid received the highest votes. The voting ratios is as below:

1. Shahla Farid: 45 votes

2.Zarqa Yaftali: 34

3. Nooria Safi: 34 votes

4. Samira Hamidi 30 votes

5. Roshan Sirran 28 votes

6.Mari Akrami: 27 votes and

7.Shafiqa Habibi 25 votes

Finally, the event was ended with prayers and wishing success to the AWN's new board members and eating launch. 